Journal of

Online and Distance

Learning

(JODL)

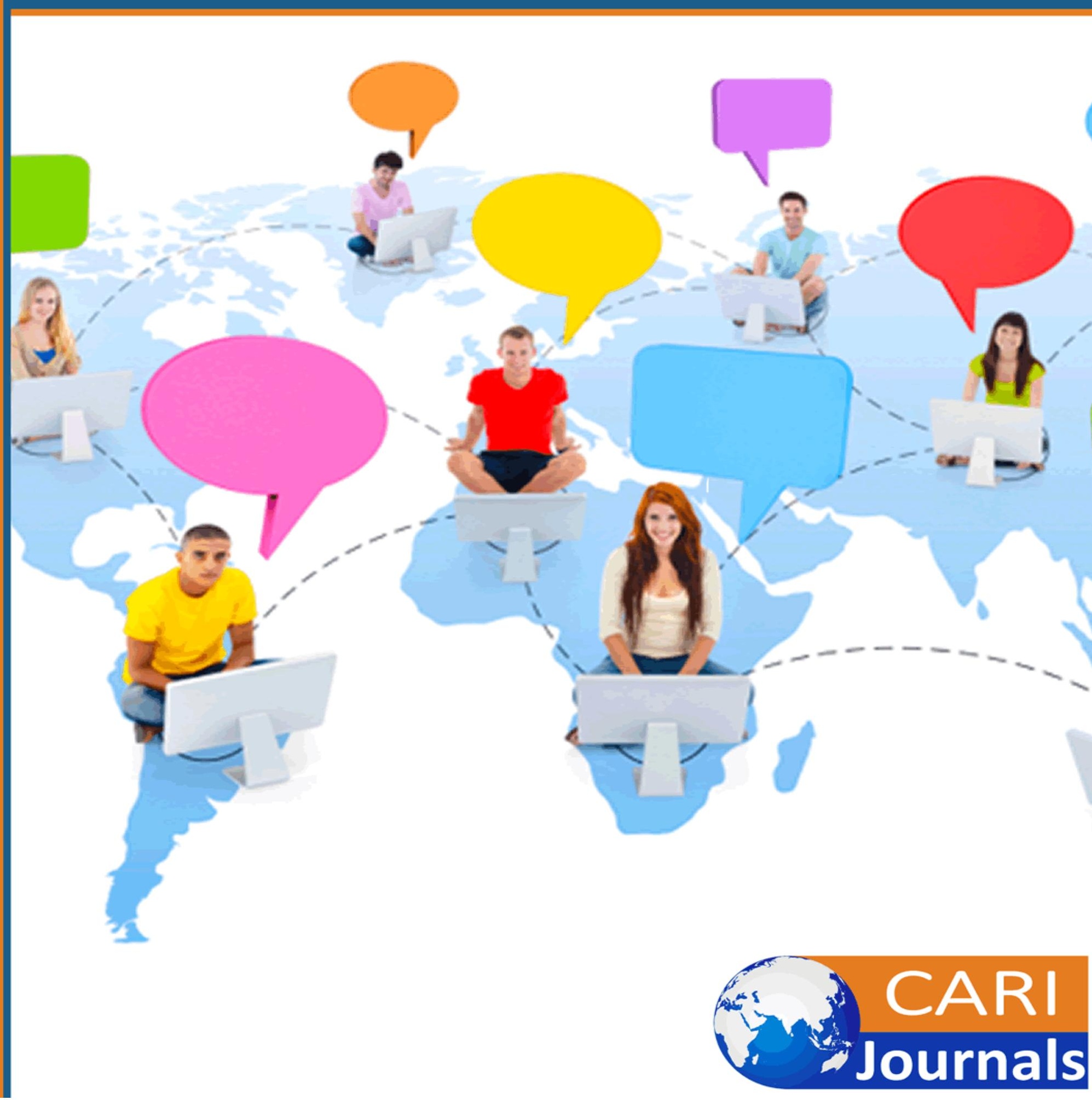




\title{
EVALUATION OF PLANNING AND MANAGEMENT OF DISTANCE EDUCATION. ACRITICAL LITERATURE REVIEW
}

\author{
Cassan Kimani, \\ Department of Education, Egerton University \\ *Corresponding author's Email: cassan@cari.org
}

\begin{abstract}
Purpose: The rapid technological changes in education today have become paramount towards meeting our educational demands for the 21st century. The emerging trend in the use of Information Communication Technology has helped in bringing down the traditional barriers of access to higher education leading to access of quality education and training. This has provided learners with opportunities for lifelong learning and meaningful participation in the world of work and society as productive citizens through distance learning. The general objective of the study was to conduct an evaluation of planning and management of distance education.
\end{abstract}

Methodology: The paper used a desk study review methodology where relevant empirical literature was reviewed to identify main themes and to extract knowledge gaps.

Findings: From the study findings, it is concluded that little difference was found in the community found in the web-based course in comparison with their traditional courses. With the special characteristics associated with distance education, special measures should be taken to see that communities are established. Choosing exercises or activities that are collaborative will increase the potential for developing a community of learners. In addition, frequent use of online discussion or bulletin boards will also assist with this endeavor. Professional development on how to build a community for traditional and web-based courses is needed.

Recommendations: The study recommends that is a need for assessment of whether or not faculty are adequately prepared to teach at a distance, especially in light of the fact that faculty tend to teach in the same manner in which they were taught, is definitely warranted. A check list that would help identify the preparedness of the faculty member before they are responsible for distance student learning would help the students and program. Instructor training should be required before faculty are considered qualified to teach distance courses which necessitates the discovery of quality training programs. Support staff that is needed to assist faculty members when making the transition from a face-to-face to a virtual environment should be identified

Keywords: evaluation, planning and management, distance, education 


\subsection{INTRODUCTION}

\subsection{Background of the Study}

Program evaluation is defined as "a process used to determine whether the design and delivery of a program were effective and whether the proposed outcomes were met" (Owen,2020). While program evaluation first focuses around this definition, important considerations often include how much the program costs per participant, how the program could be improved, whether the program is worthwhile, whether there are better alternatives, if there are unintended outcomes, and whether the program goals are appropriate and useful (Shackman,2018). Distance learning is a method of conveying education and instructions, generally on an individual basis, to the students who are not physically available in a usual setting such as a classroom. Distance learning is rapidly becoming an alternative to traditional classrooms. Students can benefit from the flexibility that comes with distance learning, and for students who don't have the time or money to attend traditional schools, distance learning can provide a path to higher education(Rao and Krishnan 2015).

Physical separation of the student and instructor for the duration of the course is one of the key identifiers for distance education. Lectures, tutorials, and for the most part, student assistance or support, is provided through electronic media (Usun, 2016). Yellen failed to mention another important component involved; distance education often possesses the characteristic of physical separation of the student from other students. Gray. (2016) felt their study of 250 institutions validated earlier study findings on characteristics of distance education programs. They agreed that there was no uniformity in the size of distance education programs; these programs were directed at capturing the nontraditional student; and faculty and student interacted by using several different forms of asynchronous and synchronous communication media. Distance education is heavily entrenched in technology. For communicating alone, there are a variety of methods. The most popular and common methods of communication used is electronic mail (e-mail); bulletin board systems (BBS); Internet (using chat programs); telephone-based audio conferencing; and video conferencing with 1 - or 2-way video and 2-way audio via broadcast; and closed-circuit or low power television (Sherry, 1996). Of the choices for course delivery, ITV (interactive television), television, video, and computer-based (web-based/Internet) (Gray,2016), web-based courses have shown to be the least expensive for institutions to provide .

Web-based courses have also experienced the greatest growth and are "the primary means by which colleges and universities provide distance learning" (Garcia, 2015) which some attribute to the cost incurred in an online course versus a video teleconferencing course (Effendi,2015). Trends provide projections on what is expected for the future. Many program decisions are made based on this invaluable information. In order for administrators to make the "right" decisions, the study of trends on all facets of distance education is required. Institution Involvement. The Internet has grown at an expeditious rate. Consider that 38 years passed before it reached 50 million users (Rakap,2015) and television was only slightly quicker, taking 30 years. The World Wide Web, on the other hand, earned that honor in only four years (Miller \& King). Technology advancements are at the heart of the increased popularity and demand of distance education statement that there is no indication of enrollments leveling off. Every one is jumping on the band wagon. A market survey administered in 2000 showed $94 \%$ of all colleges were either offering (63\%) or planning to offer $(31 \%)$ distance education courses (Dawson, 2015). Post-secondary schools are not the only 
ones 28 engaged in distance education. Business and industry are also pursing what appears to be a lucrative enterprise (Zacharius, 2011). This should come as no surprise since distance education appears to be going nowhere but straight up. Ludlow (2014) recognized the changing demographics and needs of students in higher education. He believes universities have increased their focus on recruiting students over the age of 22 since the mid-1970s. Some institutions believe distance education is the main attraction in drawing non-traditional student enrollments (Ludlow, as cited by Easton, 2003). Worley (2020) also agreed with Ludlow's statement but added that much of the growth of distance education has been fueled by those employed professionally. Traditional educational environments, for the most part, fail to provide the flexibility necessary for those with commitments to family and work. Consequently, adult learners are expounded to be one of the fastest growing groups enrolling in higher education (Worley, 2020), and to some extent, this growth is considered due to the availability of distance education (Boettcher, 2016).

Most University e-Learning programmes have been designed to increase access to higher education, especially for non-traditional students. In a recent survey on the importance of various goals to institutions' distance education program (a high proportion of which use online technology as a primary or supporting medium of instruction), two out of three United States of America fouryear public institutions indicated that increasing student access was a very important goal; either by "making courses available at convenient locations" (72\%), or by "reducing time constraints for course taking" (66\%), (Demuyakor, 2020). The corresponding figures for four-year private institutions were also high (65\% and $61 \%$ respectively). In Europe, as well, there is abundant evidence to show that widening access to their programmes - and to their related academic resources - is an important objective of many university e-learning strategies; reaching new groups of students (women and other marginalised groups) is an additional and closely related goal (UNESCO, 2000). According to (Demuyakor, 2020), Open and Distance Learning offers opportunities for countries to meet the new and changing demands for education and training. Open and Distance Learning is both complementary and under certain circumstances an appropriate substitute for the face-to-face methods that still dominate most educational systems. The advantages of Open and Distance Learning are seen more in terms of the learner through more freedom of access, and thereby a wider range of opportunities for learning and qualification. The barriers that may be overcome by distance learning include not only geographical distance, but also other confining circumstances, such as personal constraints, cultural and social barriers and lack of educational infrastructure (Ali, 2020).

For the student, it is often a cheaper alternative to pursuing a course through conventional methods. Since many people cannot afford to leave their work in order to study, it is important that distance education and training may be combined with work. Distance and Open learning may also mean a more learnercentred approach, allowing greater flexibility and choice of content as well as more personal organization of the learning programme (UNESCO 2002). Various studies have argued that the universalization of education and its worldwide acceptance as a continuous or lifelong undertaking, coupled with concerns about educational access and equity (Zhu, 2020) as well as the prevailing level of poverty, necessitate the use of various education delivery approaches to enable all citizens to benefit from this public good. 
The conventional system caters for the needs of full-time learners from a specific age group enrolled in recognized institutions of learning at various levels of the education system: primary, secondary and tertiary. The requirements of such a system, usually determined by the relevant school/university boards, largely excludes many people outside traditional school-going age groups, those who are unable to fulfil essential eligibility requirements, and those who need education and training to gain competence in jobs and upgrading of their qualifications and training (Mitra,2020). In the conventional approach the learner has to be on campus, to register as a fulltime student and to attend face-to-face lectures. Open and Distance Learning in this respect would be more appropriate to marginal populations, especially women, who in certain communities are limited by culture, poverty and tradition to access regular higher education institutions. Women face challenges of multiple roles that may limit their ability to access traditional mediums of higher education that may mean leaving work, home, or family. Wahab (2020) argues that men constitute the first and underlying cause of gender (and perhaps every other form of) inequality. "it has become the prevailing custom in many societies that the male, gradually but determinedly acquired and retained decision within the family and other institutes of the society". Making decisions in such private and public matters definitely translates into holding and retaining the power to control most affairs. And little surprise, such decisions of cause, would always be more beneficial to the male. Kerres (2020) further argues that women, no matter how educated, do not belong to the Boys'/Men's clubs, where important information is shared and crucial decisions are made. Most of these decisions may result in the marginalization of women. Studies by Hochschild (2019), involving research on women's work and family life, introduced the idea of the 'second shift', this being the home shift that women do following formal paid employment. This 'shift' involves tasks traditionally undertaken by women linked to family and community, including housework, and childcare. The American Association of University Women (AAUW) believes that education forms a 'third shift', as more and more women see education as key to future opportunity and economic wellbeing and are embarking on distance education, adding study and research to their other roles. While studies by Hochschild and later by AAUW are based on research undertaken in the United States of America, their findings are relatively universally applicable. Due to their multiple existing roles, women are particularly 'vulnerable to negative effects of adding a new role such as student to their already busy lives' ( Basilaila, 2020).

Open Distance and e-Learning as a strategy to broaden access to higher education, especially for marginalized populations, have been promoted worldwide, particularly in the last two decades. This has been mainly due to what has been perceived as the failure of the traditional higher education structures to recruit students in equal proportions from different socio-economic groups. Free and open societies should promote social mobility by developing talent in every social and ethnic group this is an issue which needs to be addressed by schools, universities, employers and governments (Brackstone 2012). It is important that higher education institutions design strategies to recruit students from a wider range of students, including those from ethnic minorities, who are underrepresented in higher education. According to Salmi and Bassert (2012), any society committed to promoting equity must ensure that their education system, including their tertiary education sector, is accessible to students from the broadest spectrum of underrepresented and traditionally-excluded groups. Salmi and Bassert (2012) argues that supporting the opportunity to seek the benefits affordable by tertiary education in an equitable manner is reasonable and 
important, as well as just, based on the widespread evidence of the many public and private benefits of attaining a college degree.

Fortunately for some students, distance education courses have resulted in an effortless switch from traditional classroom learning (Oravec, 2013). The change in instructional delivery methods, communication with the teacher and other students, and greater use of technology has not presented a challenge. Even when distance education was considered more difficult than face-toface courses, sometimes the benefits outweighed the costs. Take for example the rural, underserved learner. Distance education may have been their only alternative for receiving an education.

\subsection{Statement of the Problem}

Distance education will never replace the traditional classroom but it does provide a suitable alternative. The convenience distance education affords students helps account for its rapidly growing enrollments. These larger enrollments make distance education programs very enticing to universities and colleges. In order to have a successful program, distance education courses must be evaluated using an effective tool. The most commonly used approach to assess teaching is an evaluation completed by students (Kahn, as cited by Laverie, 2012). Results from this action increases the likelihood that important information will be missed and invalid information will appear. For many universities, distance education is a new venture and requires a great outlay of capital, making it essential that such programs reach their potential (Regalbuto, 2019). With proper evaluations of distance courses, administrators and instructors will have the guidance necessary in building successful programs. An important argument against using the same instrument with online courses as is used in traditional courses was made by Griffin, et al. (2013). They stated failure to use the proper instrument across diverse settings may result in a hindrance to course improvement and thereby lowering the quality of higher education distance programs. Moore and Kearsley cited by Miller and King (2003) and Simonson (2019) as describing distance education as essentially dissimilar from the face-to-face classroom, entailing a change in instructional methods used. Effectiveness of online teaching must be assessed to ensure quality distance education. Regalbuto (1999) reasoned the expense of technology and staff involved with distance programs, as well as pedagogic concerns, warranted the need for the appropriate evaluation tool.

Students that deviated from the norm considered the evaluation focused too much on the instructor rather than the course and that more questions directly relating to distance education factors would have improved the assessment. Even though the researchers felt the traditional evaluation form was successfully used for assessing online courses, they concluded additional studies were necessary. Regalbuto (2019) found it difficult to understand how the use of the traditional evaluation for online course evaluation could be considered successful. Regalbuto recognized the evaluation of online learning as not only complex and understated but also advised that learning is not the only area one should evaluate. Data addressing the different environmental aspects would not be included in a traditional course evaluation. Valuable information that would guide educators in regard to assessing how well the different needs of distance learners were satisfied would be completely missed. In addition, Holcomb's article unfortunately failed to go into detail on the information provided to the students prior to the survey. The main purpose of a course evaluation is to inform faculty and administration. The responses to the question posed may have reflected that the student's needs were met by the survey - a form was filled out that described the course, 
but this does not mean the faculty and administration's needs were fulfilled by the data collected on the evaluation

\subsection{Objectives of the Study}

The general objective of the study was to evaluate of planning and management of distance education.

\subsection{Justification and Significance of the Study}

Distance education is one of the newest players on the field of education. Due to its recognized importance to higher education, every facet is scrutinized. Institutions are interested in learning if the correct teaching methods are used, whether or not proper use of technology is occurring, and if students are truly learning as well as they would in a 16 traditional classroom. The purpose of this study is to assist in providing information that will help institutions develop a distance education evaluation system by creating or choosing a proper student evaluation instrument and procedures that will provide valid and reliable answers in order to make applicable decisions. In this case, the adage, "what you don't know, can't hurt you" is definitely a misnomer. Information will be gathered on web-based courses in particular. This information may be useful when looking at other distance education type courses. It is important to note possible improvements to traditional evaluation systems would also be a possible result of this study.

\subsection{LITERATURE REVIEW}

\subsection{Theoretical review}

Two theories were found to be relevant in evaluate of planning and management of distance education. The theories that were found to best inform the research constructs are Paradigm shift theory, (1962) and Technology Acceptance Model Theory (Vankatesh, 2008).

\subsubsection{Paradigm Shift Theory}

According to Kuhn T. (1962), scientific revolution occurs when scientist uncounted anomalies which cannot be explained by the universally accepted Paradigm within which scientific progress has thereto been made. While applying the concept of paradigm within social context in addressing issues of changing paradigm, process popularly called paradigm shift, Handa (2012) shows how the shift affects social institutions in order to meet social needs and bring the desired social change. In this study, the current institutional-based access to university education highly favours male students and females from metropolitan regions. These ones do not face many barriers in their access to higher education. To broaden access to female students from Arid and Semi-Arid regions, who face many barriers in their attempt to access university education, there is a need for a paradigm shift to Open Distance and eLearning. In this context, the study attempted to find out whether Open Distance and eLearning and using student centred approaches for women had any impact in increasing female participation in higher education. In this current shift, Open Distance and e-Learning and student-centred approaches puts 'other groups` (women, marginalized communities) as on the same footing with dominant groups (men and women from metropolitan regions). The inflexible admission, selection and entry requirements by Joint Admissions Board and on-campus admission have limited the access of women from Arid and Semi-Arid and 
marginalized communities to higher education. Thus, such has to be replaced by a flexible admission and selection programme which caters for learner's needs and constraints of time, space, resources and socio-economic disabilities faced by women. This will give these hundreds of Kenyan women hope or a chance to 25 juggle multiple roles in society while they continue learning. With Open Distance and e-Learning there will be a shift from face-to-face, teacherlearner approach where the learner is passive, communication is one way, and learner is not involved in development of knowledge. Hence, the paradigm shift would involve learner-instructor approach where the learner is active, communication is two way and the learner is involved in knowledge development, decision making on what to learn, how and when to learn.

\subsubsection{Technology Acceptance Model Theory}

This study adopted the Technology Acceptance Model Theory (TAM) of Vankatesh \& Bala (2008) which is greatly referred to as Information System Theory (IST). This theory shows how the users take time to accept and use any new technology disposed to them. Vankatesh and Balla (2008) emphasize that technologies which are new like personal computers or any other, are complicated from the beginning and there exist an element of uncertainty in the minds of the maybe makers of decisions with respect to adopting them successfully. In this situation people form intentions and attitudes towards making effort in learning how to use the technology that is new before initiation of efforts which are directed at using. Attitudes towards using and the intentions to use can be poorly-formed or lack conviction or else can only occur only after preliminary striving in learning how to use the new technology that evolves. This means that the real usage may not have immediate or direct consequence of such intentions and attitudes. The Technology Acceptance Model Theory continues to state that subject norms, perceived behavioral control and attitudes shape every individual intention it takes in engagement in a specific time and place. Behavioral intentions are influenced by the attitudes of individuals basing on pre-expected outcomes in terms of risks and benefits not yet seen or experienced. Behaviour depends on both motivation (intension) and (behavioral control). The six constructs influencing a person's behavior are namely; attitude to evaluate, strength of intension, degree of approval (are many people benefiting?), social norms-(what is the trend?) Power of impediments (can I get over or not?), perceptions- (easy or difficult?).This theory will add to the study as it helps in evaluation of adoption of modern online learning as transits from the traditional learning process

\subsection{Empirical Review}

Mugia,(2016) conducted a study to review the program evaluation strategies in point of suitabilities to distance education. In the study, it was used of literature review technique to gather data. Firstly, relevant and previous studies in the literature on the program evaluation strategies in distance education were searched and in detailed reviewed. Then, thirteen evaluation strategies that were frequently used to collect data for educational program evaluations were described and reviewed in point of suitabilities and utilities to distance education. In conclusion, it was determined that the objectives-oriented strategy and systems -based evaluation strategies were highly suited to distance education programs. But, traditional, expertise-oriented, humanistic and academic evaluation strategies were not suited to distance education programs. The conclusions obtained in this study may be useful in the exploration of further research areas in the field of program evaluation in distance education. In future, qualitative and / or quantitative researches 
should be realized on the suitabilities of the strategies of the objectives-oriented and systems based evaluation for distance education program.

Keta, (2011) conducted a study to evaluate the planning and management of distance education with focus on Kenya Institute of Special Education (KISE) DE Programme. With the gap realized by the Ministry of Education during external evaluation of teaching practice in the year 2004, the quality of DE due to increased enrolment seemed to be in conflict with quality of residential students. The study begun by taking a look at ODL in developed and developing countries. How DE developed in Kenya and differences in conventional and education at a distance. The objective of the study therefore focused on how DE is planned and managed in terms of admission requirements, physical facilities, human and financial resources required for learning. The research design used was case study which is mostly used in evaluating a specific programme, and the data collected is interpreted and recommendations are made for programme improvement. The study was located widely all over Kenya covering different districts within 18 contact centers for the KISE DE Programme. The target population comprised of all third years KISE Diploma DE Learners, Sampling technique is mixed due to the great number of sample distributed all over the country, random and non-random sampling techniques were used. The sample was drawn from 7 contact centers using systematic sampling and the sample was picked using fraction sample on the class lists. A questionnaire for learners were the instrument used for data collection, data analysis involved both qualitative and quantitative methods. The qualitative data derived from responses were analyzed in. narrative form and quantitative data was analyzed using simple descriptive statistics. Illustrations in the form of tables were used to present the data and result findings were presented under themes. The study revealed that Distance Delivery Mode is a lonely mode of study since the learners are on there on most of the time. As such putting together learners support services that are responsive to the academic, social and individual needs of learners becomes critical. It is quite evident in the findings that adult learners in the DE programme are in dire need of support services. Among the recommendations made, there is need for the government to develop a supportive and comprehensive national policy framework at the national level. There is need to ensure access to quality DE, use of informational and communication technology and other media in provision of DE. There is need for Kenya to link with other countries who have developed ODL programmes

Laichena , (2017) conducted a study set out to ascertain the types of learner support services offered to open, distance and e-learning students as well as identify learner support services that the students and the administrators felt were essential for effective learning. The study also intended to establish the attitudes of the users of open, distance and e-learning programmes on the learner support services offered and identify the factors that influence learner support services offered in open, distance and e-learning programmes in selected public universities in Kenya. The study limited itself to fourth year students undertaking a bachelor's degree programme only. This study was guided by the systems approach model whereby the types of learner support services offered by an institution enhances the success of open, distance and e-learning programmes through provision of adequate learner support services. Literature reviewed on the categories of services such as teaching and learning needs, access of information and personal and social needs (independent variables) showed that they determine the overall satisfaction of learner support services (dependent variable) offered. 
The study adopted a descriptive survey design. Purposive sampling was used to select three public universities offering open, distance and e-learning programmes, namely Egerton University, Kenyatta University and the University of Nairobi. Further, purposive sampling method was also used to select three study regions where each of the three universities had a study centre. A sample size of 329 fourth year students in the selected universities was arrived at using tables instituted by Morgan and Krejcie (1970). Stratified sampling technique was used to get a representation of students from each university while convenience sampling was used to select the students at each study centre from each university. All the administrators (directors and coordinators) were used in the study. The study instruments (interview schedules and questionnaires) were constructed to help in data collection. The data collected was coded, analysed and tabulated using the SPSS version 20 programme. Results were presented in form of frequency distribution tables and graphs. The study established that students rated majority of learner support services offered by their institutions across the three universities as poor while the administrators indicated that the services offered were good. However, the students and the administrators were of the opinion that there were essential learner support services that were very necessary to open, distance and e-learning students. Further, there was a consensus by the students and the administrators that the services offered were necessary though they needed to be improved. Lastly, the study found out that the administrators were aware of the essential learner support services but were limited by other factors that were beyond their control. The study recommends that; institutions offering open, distance and e-learning programmes should constantly assess the value of learner support services offered by constantly seeking the students ${ }^{\text {ee }}$ opinion and offer few but essential learner support services that are of high quality, adequate, of good quality and satisfactory to the students.

Mbithi, (2013) conducted a survey of Open, Distance and Electronic Learning Mode in Kenyan Universities with a bias to Administration, Delivery and Evaluation functions. The study also considered involvement of some project management concepts in the running of ODeL programmes in Kenyan Universities. The study involved four Universities. The research design was descriptive and the respondents were selected using stratified random sampling. Closed and open questionnaires were distributed randomly to a representative sample of the population which was used to collect data. The data was then recorded and coded in Microsoft excel soft ware for analysis, interpretation and representation. The study found out that Kenyan Universities are providing ODeL students with most of the necessary support services in terms of content access, participation, orientations as well as creating a conducive environment for learning especially to those students who would have missed the access for higher education through face- to - face interaction. However, the study found out that Kenyan Universities lack some more effective interactive modem information technologies as compared to Open Universities from developed countries.

Sona,(2013) conducted a study that sought to establish the effect of IBT on the teaching methods, establish the effect of academic best practices on the learning culture and investigate the effect of IBT on policy formulation of Kenyatta University City Campus. The researcher used case study research design purposively selected 120 respondents. This comprised of 100 students selected from four departments, 10 administrators and 10 lecturers. Primary data was collected using selfadministered questionnaires. The collected quantitative data has been analysed using descriptive statistics. In addition, content analysis was used for qualitative data. To aid data analysis the 
researcher used the statistical package for social sciences (SPSS). The study found out that respondents preferred online materials and that internet had helped in reducing the duration for doing assignments, and internet has improved inter-campus sharing. Internet availability had also improved the quality of assignments and has improved the overall conceptualization of ideas and subjects by students. The respondents also used internet for academic research, social interactions, and games as well as for business purposes. The students also agreed that they spent more and unnecessary time on social websites, internet games than on academic research, students accessed and download the wrong materials from the university web access points, and students directly downloaded class assignments and presented them without their own input, since they found it is easier to download class assignments. Generally, the results indicate that internet use have had a negative effect on the learning and as well teaching within the City Campus. Internet also had influenced learning abilities of students by reducing class attendance by avoided lessons since they could easily access notes online, lack of in-depth research from different source (prefer internet) among other negative aspects. The respondents preferred online/distance and e-learning methods to traditional classroom lectures, indicating the need to respond to the new challenges and needs of the students by adopting internet based teaching methodologies. On whether the policy framework had been modified since the advent of internet based teaching and learning within the university education, the $50 \%$ the respondents agreed that it had been modified while the other $50 \%$ did not agree. The study also found out that plagiarism could not be stamped out with the advent of the internet based learning. The learning culture had also changed with the internet with students no longer appreciating classroom-setting lectures, nor hard copies of notes rather they would appreciate more the online notes and other online functionaries like submission of assignments through internet.

\subsection{Research gaps}

Geographical gap is a knowledge gap that considers, the untapped potential or missing/limited research literature, in the geographical area that has not yet been explored or is under-explored. For instance, Keta, (2011) conducted a study to evaluate the planning and management of distance education with focus on Kenya Institute of Special Education (KISE) DE Programme. The study revealed that Distance Delivery Mode is a lonely mode of study since the learners are on there on most of the time. As such putting together learners support services that are responsive to the academic, social and individual needs of learners becomes critical. The study presented a geographical gap as it was done in Nairobi while our current study sought to evaluate of planning and management of distance education.

Methodological gap is the gap that is presented as a result in limitations in the methods and techniques used in the research (explains the situation as it is, avoids bias, positivism, etc. Laichena , (2017) conducted a study set out to ascertain the types of learner support services offered to open, distance and e-learning students as well as identify learner support services that the students 
and the administrators felt were essential for effective learning. The study adopted a descriptive survey design. Purposive sampling was used to select three public universities offering open, distance and e-learning programmes, namely Egerton University, Kenyatta University and the University of Nairobi.The the study found out that the administrators were aware of the essential learner support services but were limited by other factors that were beyond their control. The study recommends that; institutions offering open, distance and e-learning programmes should constantly assess the value of learner support services offered by constantly seeking the studentse opinion and offer few but essential learner support services that are of high quality, adequate, of good quality and satisfactory to the students. The study presented a methodological gap as it was subjected to descriptive research design while our current study adopted a desktop literature review method.

Conceptual gap arises because of some difference between the user's mental model of the application and how the application actually works. Mbithi, (2013) conducted a survey of Open, Distance and Electronic Learning Mode in Kenyan Universities with a bias to Administration, Delivery and Evaluation functions. The research design was descriptive and the respondents were selected using stratified random sampling. The study found out that Kenyan Universities lack some more effective interactive modem information technologies as compared to Open Universities from developed countries. The study presented a conceptual gap as it investigated a survey of Open, Distance and Electronic Learning Mode in Kenyan Universities with a bias to Administration, Delivery and Evaluation functions while our current study will focus on advantage of adoption of Open Distance and e-Learning to increase access to female in higher education.

\subsection{METHODOLOGY}

The study adopted a desktop literature review method (desk study). This involved an in-depth review of studies related to evaluation of planning and management of distance education. Three sorting stages were implemented on the subject under study in order to determine the viability of the subject for research. This is the first stage that comprised the initial identification of all articles that were based on evaluation of planning and management of distance education from various data bases. The search was done generally by searching the articles in the article title, abstract, keywords. A second search involved fully available publications on the subject on evaluation of planning and management of distance education. The third step involved the selection of fully accessible publications. Reduction of the literature to only fully accessible publications yielded specificity and allowed the researcher to focus on evaluation of planning and management of distance education which was split into top key words. After an in-depth search into the top key words (evaluation, planning and management, distance, education), the researcher arrived at 6 articles that were suitable for analysis. The 5 articles were findings from Mugia, (2016) who conducted a study to review the program evaluation strategies in point of suitabilities to distance education. In the study, it was used of literature review technique to gather data. In conclusion, it was determined that the objectives-oriented strategy and systems -based evaluation strategies were highly suited to distance education programs

Keta, (2011) who conducted a study to evaluate the planning and management of distance education with focus on Kenya Institute of Special Education (KISE) DE Programme. The study 
revealed that Distance Delivery Mode is a lonely mode of study since the learners are on there on most of the time. As such putting together learners support services that are responsive to the academic, social and individual needs of learners becomes critical.

Laichena , (2017) conducted a study set out to ascertain the types of learner support services offered to open, distance and e-learning students as well as identify learner support services that the students and the administrators felt were essential for effective learning. The study adopted a descriptive survey design. Purposive sampling was used to select three public universities offering open, distance and e-learning programmes, namely Egerton University, Kenyatta University and the University of Nairobi. The the study found out that the administrators were aware of the essential learner support services but were limited by other factors that were beyond their control. The study recommends that; institutions offering open, distance and e-learning programmes should constantly assess the value of learner support services offered by constantly seeking the students ${ }^{\text {ee }}$ opinion and offer few but essential learner support services that are of high quality, adequate, of good quality and satisfactory to the students.

Mbithi, (2013) conducted a survey of Open, Distance and Electronic Learning Mode in Kenyan Universities with a bias to Administration, Delivery and Evaluation functions. The research design was descriptive and the respondents were selected using stratified random sampling. The study found out that Kenyan Universities lack some more effective interactive modem information technologies as compared to Open Universities from developed countries.

Sona,(2013) conducted a study that sought to establish the effect of IBT on the teaching methods, establish the effect of academic best practices on the learning culture and investigate the effect of IBT on policy formulation of Kenyatta University City Campus. The researcher used case study research design purposively selected 120 respondents. This comprised of 100 students selected from four departments, 10 administrators and 10 lecturers. Primary data was collected using selfadministered questionnaires. The results indicate that internet use have had a negative effect on the learning and as well teaching within the City Campus. Internet also had influenced learning abilities of students by reducing class attendance by avoided lessons since they could easily access notes online, lack of in-depth research from different source (prefer internet) among other negative aspects.

\subsection{SUMMARY, CONCLUSION AND POLICY IMPLICATION FOR FURTHER STUDY}

\subsection{Summary}

Evaluation is one of the critical steps in the process of performance improvement. Evaluation feeds evidence based information back to the next cycle of performance improvement. However, organizations often neglect to conduct comprehensive evaluations on their programs due to environmental barriers or the lack of practitioners' evaluation expertise (Chyung ,2015). Generally, evaluation is used to determine the degree to which program objectives are met through the procedures used by the program. The evaluation determines whether or not the outcomes or results predicted by the program occurred and if their occurrence was due to the project. It is essential that evaluation and feedback be part of all distance learning programs. Evaluation in distance education must be carefully balanced between a traditional view that allows for program 
justification/development and a new view that has the potential for empowering. Also, evaluation in distance education is undertaken to guide decision-makers program leaders, program coordinators with an overall objective to improve service delivery and client satisfaction. Evaluation commonly aims to determine the relevance, efficiency, effectiveness, impact and sustainability of a distance education program or project.

\subsection{Conclusion}

From the study findings, it is concluded that little difference was found in the community found in the web-based course in comparison with their traditional courses. With the special characteristics associated with distance education, special measures should be taken to see that communities are established. Choosing exercises or activities that are collaborative will increase the potential for developing a community of learners. In addition, frequent use of online discussion or bulletin boards will also assist with this endeavor. Professional development on how to build a community for traditional and web-based courses is needed.

\subsection{Recommendations}

The study recommends that is a need for assessment of whether or not faculty are adequately prepared to teach at a distance, especially in light of the fact that faculty tend to teach in the same manner in which they were taught, is definitely warranted. A check list that would help identify the preparedness of the faculty member before they are responsible for distance student learning would help the students and program. Instructor training should be required before faculty are considered qualified to teach distance courses which necessitates the discovery of quality training programs. Support staff that is needed to assist faculty members when making the transition from a face-to-face to a virtual environment should be identified

\subsection{REFERENCES}

Ali, W. (2020). Online and remote learning in higher education institutes: A necessity in light of COVID-19 pandemic. Higher Education Studies, 10(3), 16-25.

Ali, Wahab. "The Efficacy of Evolving Technology in Conceptualizing Pedagogy and Practice in Higher Education." Higher Education Studies 9, no. 2 (2019): 81-95.

Dawson, B. A., \& Fenster, J. (2015). Web-based social work courses: Guidelines for developing and implementing an online environment. Journal of Teaching in Social Work, 35(4), 365-377.

Demuyakor, J. (2020). Coronavirus (COVID-19) and online learning in higher institutions of education: A survey of the perceptions of Ghanaian international students in China. Online Journal of Communication and Media Technologies, 10(3), e202018.

Effendi, H., Soenarto, S., \& Sofyan, H. (2015). The effectiveness of web-based interactive blended learning model in electrical engineering courses. REiD (Research and Evaluation in Education), 1(2), 175-185. 
Garcia, I., Guzmán- Ramírez, E., \& Pacheco, C. (2015). CoLFDImaP: A web- based tool for teaching of FPGA- based digital image processing in undergraduate courses. Computer Applications in Engineering Education, 23(1), 92-108.

Gray, J. A., \& DiLoreto, M. (2016). The effects of student engagement, student satisfaction, and perceived learning in online learning environments. International Journal of Educational Leadership Preparation, 11(1), n1.

Kapasia, N., Paul, P., Roy, A., Saha, J., Zaveri, A., Mallick, R. \& Chouhan, P. (2020). Impact of lockdown on learning status of undergraduate and postgraduate students during COVID19 pandemic in West Bengal, India. Children and Youth Services Review, 116, 105194.

Kerres, M. (2020). Against all odds: Education in Germany coping with Covid-19. Postdigital Science and Education, 2(3), 690-694.

Mbithi, B. M. (2013). Influence of financial transactions through mobile phones on the growth of Safaricom agents in Kisumu county, Kenya (Doctoral dissertation, University of Nairobi).

Mitra, S., \& Mitra, J. C. Education after covid-19 (real pandemic). : 2020, 187.

Murphy, M. P. (2020). COVID-19 and emergency eLearning: Consequences of the securitization of higher education for post-pandemic pedagogy. Contemporary Security Policy, 41(3), 492-505.

Oirere, G. G. Month: August 2018.

Owen, J. M. (2020). Program evaluation: Forms and approaches. Routledge.

Rakap, S., Jones, H. A., \& Emery, A. K. (2015). Evaluation of a web-based professional development program (Project ACE) for teachers of children with autism spectrum disorders. Teacher Education and Special Education, 38(3), 221-239.

Rao, S., \& Krishnan, V. (2014, December). Distance education. In Nitte University, Fourth International Conference on Higher Education: Special Emphasis on Management Education.

Sahu, P. (2020). Closure of universities due to coronavirus disease 2019 (COVID-19): impact on education and mental health of students and academic staff. Cureus, 12(4).

Shackman, G. (2018). What is Program Evaluation? A Beginners Guide (Presentation Slides). A Beginners Guide (Presentation Slides) (February 11, 2018).

UŞUN, S. (2016). A review on the program evaluation strategies in distance education. International Journal on New Trends in Education \& Their Implications (IJONTE), 7(3).

WANJIRU, M. J. (2018). Determinants of utilization of government online services in Kenya: case of national transport and safety authority Nairobi (Doctoral dissertation, kenyatta university). 
Zacharis, N. Z. (2011). The effect of learning style on preference for web- based courses and learning outcomes. British Journal of Educational Technology, 42(5), 790-800.

Zhu, X., \& Liu, J. (2020). Education in and after Covid-19: Immediate responses and long-term visions. Postdigital Science and Education, 2(3), 695-699. 